\title{
FAILURE CAUSES AND EFFECT ANALYSIS OF WATER SUPPLY SYSTEMS
}

\author{
Ionescu Gheorghe - C-tin ${ }^{*}$ \\ Ionescu Daniela - Smaranda ${ }^{* *}$ \\ Daroczi Carol ${ }^{* * *}$
}

The present paper intends to overview the problems of the failure causes and effect analysis of water supply systems. The author's efforts were channeled to systemizing, classifying and adapting the content to the hydraulics engineering field.

\section{Failure Causes}

In the analysis of failure possibilities, of noticing the secondary faults and foreseeing the adequate compensatory measures, the identification and description of all the potential causes of each analyzed failure mode is necessary.

The analysis of the faults has been done together with the identification of failure modes.

The failure effects, the consequences of each failure mode has been estimated both at the level of the analyzed component, and also at the superior level.

The local effect notion means the consequences of the failure mode upon the studied element from the system. The description of the local consequences, and also of the secondary effects, have led to establishing the replacement or recommendation of adequate correct actions solutions.

The general effect notion (at the system level) means the influence of a possible failure upon the highest level of the system. Generally, the final effect is produced by a multiple fault or failure, fact which implies the analysis of all the superior intermediary levels of the production spot up to the highest level.

Each analyzed failure mode needs the methods signals by which it can be identified. As the analyzed water supply system incorporates

\footnotetext{
* Ph.D.Prof.Eng. UNIVERSITY OF ORADEA - ROUMANIE

${ }^{\star *}$ Ph.D.Assoc.Prof.Eng. UNIVERSITY OF ORADEA - ROUMANIE

${ }^{* *}$ Ph.D.Assoc.Prof.Eng. UNIVERSITY OF ORADEA - ROUMANIE
} 
redundant elements, the notification of the identification method or methods of their failure during normal functioning, is necessary.

The existence of a flaw in the system implies the implementation of some compensatory measures, which measures seek both the prevention and also the reduction of the consequences of the analyzed failure mode.

In order to optimize the reliability of a water supply system, the prevention methods are very important and not the solutions for fixing the faults, in consequence the use of the following procedures is recommended:

Reducing the possibility of a failure by using some safety devices and an adequate maintenance;

Limiting the effect propagation in the system by using some structures or redundant elements, as well as signaling and alarm devices;

Diminishing the consequences' gravity by using diverse protection devices or the existence of store elements which automatically undertake the tasks of the fault phase.

\section{Risk Evaluation}

The risk evaluation for each analyzed failure mode is done on the basis of some gravity (of consequences) rate scales and the possibility of producing these events.

By establishing a scale of values which should allow the estimation of consequences' gravity according to certain criteria, we can define the criticality and risk concept. The relevant criteria which establish the risk degree are the following:

1. accidents (injury, death) of persons;

2. the loss of one or more functions of the system;

3. affecting the environment;

4. the equipment's failure.

Estimating the emergence of a failure mode frequency can be done in two ways:

a) determining the gravity level of failure mode on the basis of failure rates afferent to the systems' elements;

b) evaluating the failure modes identified in F.M.E.C.A (Failure mode and effect and criticality analysis) in terms of achievement probability.

In the following table is presented the estimation mode of the gravity level for the analyzed water supply system, taking into account the criteria mentioned before. 


\begin{tabular}{||c|l||}
\hline $\begin{array}{c}\text { Level of } \\
\text { Gravity }\end{array}$ & \multicolumn{1}{|c|}{ Defining Conditions } \\
\hline \hline 1 & $\begin{array}{l}\text { Susceptible of harming the well functioning of the system, negligible } \\
\text { deteriorations on the system and the environment, without risk for people. }\end{array}$ \\
\hline 2 & $\begin{array}{l}\text { It harms the well functioning of the system, without important } \\
\text { deteriorations and without presenting a considerable risk for people. }\end{array}$ \\
\hline 3 & $\begin{array}{l}\text { The loss of one or more essential functions of the system, important } \\
\text { deteriorations of the system and environment, presenting a negligible risk } \\
\text { in harming or death of people. }\end{array}$ \\
\hline 4 & $\begin{array}{l}\text { The loss of one or more essential functions of the system, important } \\
\text { deteriorations of the system and environment, presenting an imminent risk } \\
\text { in harming or death of people. }\end{array}$ \\
\hline
\end{tabular}

In the second case, the estimation of the production probability levels for the failure modes is done on the basis of the proportion out of the total probability failure $\mathrm{F}(\mathrm{t})$ of the system for a given operation time. In the analysis for the technical and technological systems, the general probability levels are:

1. very low probability: $<0,01 \mathrm{~F}(\mathrm{t})$;

2. reduced probability: $(0,01 \ldots 0,1) \mathrm{F}(\mathrm{t})$;

3. medium probability: $(0,1 \ldots 0,2) \mathrm{F}(\mathrm{t})$;

4. high probability: $>0,2 \mathrm{~F}(\mathrm{t})$.

By evaluating the probability and risk degree of a failure emergence, the quantitative estimation of the risks associated to the different failure modes of the system becomes possible.

Frequently, for evaluating the risk associated to the failure modes, a matrix is used, called the risk matrix, which contains the levels of gravity in the $y$-coordinate, and in the x-coordinate - the probability levels of the failures. The risk class is expressed with the help of a number made up of two digits, resulting from the combination of the gravity level with the probability one.

The next step consists in the area delineation of the risk matrix in the acceptable risk areas, respectively, unacceptable.

The correction measures will be applied according to the acceptability area, respectively, unacceptability in which each failure mode is situated.

The evaluation of the risk level and the security level is done on the basis of the gravity-probability couple, according to the following table: 


\begin{tabular}{|c|l|l||}
\hline $\begin{array}{c}\text { GRAVITY-PROBABILITY } \\
\text { LEVEL }\end{array}$ & \multicolumn{1}{|c|}{ RISK LEVEL } & \multicolumn{1}{|c|}{$\begin{array}{c}\text { SECURITY } \\
\text { LEVEL }\end{array}$} \\
\hline \hline$(1.1) ;(1.2) ;(1.3) ;(1.4)$. & $1-$ MINIMUM & $4-$ MAXIMUM \\
\hline$(2.1) ;(2.2) ;(2.3) ;(2.4)$. & $2-$ LOW & $3-$ HIGH \\
\hline$(3.1) ;(3.2) ;(3.3) ;(3.4) ;(4.1)$. & $3-$ HIGH & $2-$ LOW \\
\hline$(4.2) ;(4.3) ;(4.4)$. & $4-$ MAXIMUM & $1-$ MINIMUM \\
\hline
\end{tabular}

F.M.E.C.A.: Failure mode and effect and criticality analysis is a method currently used in engineering practice analysis of reliability and security of technical systems and which presents both advantages and disadvantages.

following:

Among the method's main advantages we can enumerate the

$\checkmark$ it achieves a systematical identification of the cause and effect relations;

$\checkmark$ it permits the identification of critical failure modes;

$\checkmark$ it offers information about the propagation in the system of singular failures;

$\checkmark$ it investigates, identifies and evaluates the production causes and consequences as compared to normal or faulted functioning of the system.

Among the disadvantages of the method we can enumerate:

$>$ the method becomes impractical when a direct relationship between cause and effect cannot be realized;

$>$ the analysis of the temporal variable events, of the reinstatement processes, of the maintenance, of the ambient conditions, etc. are completed with great difficulty;

$>$ the complex interactions between the failures of the different elements of the system cannot be molded easily;

$>$ it doesn't allow a single quantitative evaluation;

$>$ the number of discharge data is higher, even for systems of low complexity.

The failure categories frequently used in the F.M.E.A. (Failure mode and effect analysis) or A.M.D.E.C. according to the risk level are the following: 


\begin{tabular}{|c|c|l||}
\hline $\begin{array}{c}\text { Failure } \\
\text { category }\end{array}$ & $\begin{array}{c}\text { Risk } \\
\text { level }\end{array}$ & \multicolumn{1}{|c|}{ Defining conditions } \\
\hline \hline 1 & 4 & $\begin{array}{l}\text { Catastrophic failure: the failure cannot be foreseen } \\
\text { by examination or supervision and it produces the } \\
\text { total or partial loss of the system's function. }\end{array}$ \\
\hline 2 & 3 & $\begin{array}{l}\text { Critical failure: failure capable to cause injuries or } \\
\text { death to people, as well as important material losses. }\end{array}$ \\
\hline 3 & 2 & $\begin{array}{l}\text { Major failure: failure susceptible of reducing the } \\
\text { capability of a more complex device to fulfill the } \\
\text { specified function. }\end{array}$ \\
\hline 4 & 1 & $\begin{array}{l}\text { Minor failure: failure which is not susceptible of } \\
\text { reducing the capability of a device to fulfill the } \\
\text { specified function. }\end{array}$ \\
\hline
\end{tabular}

\section{Bibliography}

1. BĂLAN, A. G. - The Optimization of the Water Cleaning Process in the Suspension Separators with Variable Volume, $\mathrm{PhD}$. Thesis, 1997.

2. FELEA, I. - The Reliability Engineering in the Electro-Energetic Field, Didactică şi Pedagogică Publishing House, R.A., Bucureşti, 1997.

3. IANCULESCU, O., IONESCU, GH. - Water Supply Systems, Imprimeria de Vest Oradea Publishing House, 1999.

4. IONESCU, GH. C. - Water Supply Installations, Matrix Rom Publishing House - Bucureşti, 2004.

5. IONESCU, GH. C. ş. a. - The Reliability of Hydraulic Installations, Treira Publishing House, Oradea, 2000.

6. IONESCU, GH. C. - Contributions to the Study and Optimization of the Hydraulic Installations Reliability within the Water Supply Systems in Urban Areas. PhD Thesis, 2003.

7. IONESCU, GH. C. - The Optimization of the Hydraulic Installations within the Water Supply Systems, MatrixRom Publishing House - Bucureşti, 2004.

8. IONESCU, GH. C., IONESCU G.L. - Water Supply Systems, Matrix Rom Publishing House - Bucureşti, 2010.

9. TRAIEAN ŞERBU - The Reliability and the Installations Risk. Theory and Calculus Elements. Matrix Rom. Publishing House, Bucureşti, 2000. 
10. IVAS, D., MUNTEANU, FL. ş. a. - Reliability - Maintenance Availability - Improvement in Hydro-Energetic Field. Prisma Publishing House, Rm. Vâlcea, 2000. 